\title{
GERENCIAMENTO DE RESULTADOS FINANCEIROS EM OFERTAS PÚBLICAS INICIAIS DE AÇÕES (IPOS) E DESEMPENHO POSTERIOR DAS AÇÕES
}

\section{EARNINGS MANAGEMENT IN INITIAL PUBLIC OFFERINGS (IPOS) AND SUBSEQUENT STOCK PERFORMANCE}

\section{GESTIÓN DE INGRESOS EN OFERTAS PÚBLICAS INICIALES (OPI) Y RENDIMIENTO POSTERIOR DE ACCIONES}

Paulo Henrique Fonseca de Melo

Mestre em Ciências Contábeis pela Universidade Federal de Minas Gerais. Superintendente de Controladoria e Finanças da MGS S.A.

phfons@gmail.com

Wagner Moura Lamounier

Doutor em Economia pela Universidade Federal de Viçosa - UFV. Professor Associado da Universidade Federal de Minas Gerais - UFMG. Professor e pesquisador do programa de PósGraduação em Controladoria e Contabilidade da Universidade Federal de Minas Gerais $\mathrm{PPGC/UFMG}$

wagner@face.ufmg.br

https://orcid.org/0000-0001-7154-6877

\section{Editor Científico: José Edson Lara}

Organização Comitê Científico

Double Blind Review pelo SEER/OJS

Recebido em 02.12.2019

Aprovado em 07.05.2020 


\section{Resumo}

1) Gerenciamento de Resultados Financeiros em Ofertas Públicas Iniciais de Ações (IPOs) e Desempenho Posterior das Ações

2) Objetivo do Estudo: Procurou-se na presente pesquisa verificar se as empresas brasileiras que realizaram IPO recentemente na Bolsa de Valores gerenciaram seus resultados, melhorando-os nos períodos próximos ao lançamento e, em consequência, apresentaram desempenho ruim no longo prazo, fruto das reversões dos accruals contábeis relativos ao gerenciamento.

3) Metodologia/abordagem: Utilizou-se uma abordagem positiva/quantitativa de pesquisa tendo como técnica principal a estimação e análise dos modelos de regressão propostos por Kothari, Leone e Wasley (2005) e o modelo de Dechow, Sloan e Sweeney (1995) para avaliar a possibilidade de que as empresas possam estar gerenciando seus resultados contábeis antes de IPOs.

4) Originalidade/Relevância: A Análise ora implementada é relevante, pois objetiva elucidar para os investidores no mercado de capitais se a as firmas tendem a gerenciar seus resultados afim de obter melhores preços para suas ações, beneficiando-se de uma falha de mercado ligada à assimetria informacional existente entre os seus gestores (melhor informados) e seus potenciais investidores, com piores informações sobre a empresa.

5) Principais Resultados: Foram avaliados 92 IPOs ocorridos no Brasil. Quanto às métricas de performance analisadas, pôde-se inferir que os gestores, aparentemente, tem gerenciando os resultados das firmas no intuito de melhorar estes indicadores nos momentos que antecedem o lançamento das ações objetivando reação positiva do mercado. Por fim, observou-se também que, para todos os períodos posteriores analisados $(\operatorname{anos}+1,+2 \mathrm{e}+3)$, o retorno médio das ações das empresas IPO com menores níveis de accruals discricionários (não gerenciadoras) foram maiores do que o retorno médio apresentado pelas empresas IPO com maiores níveis de accruals discricionários (gerenciadoras).

6) Contribuições teóricas/metodológicas: $O$ trabalho pode evidenciar uma melhor adequação do modelo de "Performance-Matching" de Kothari, Leone e Wasley (2005) em relação ao modelo tradicional de análise de Gerenciamento de Resultados de Dechow, Sloan e Sweeney (1995) para fins de estimação e identificação da prática de gerenciamento de resultados nas firmas.

7)

Palavras Chave: Gerenciamento de Resultados, Performance Econômico-financeira, Retorno das Ações, Accruals contábeis.

\footnotetext{
Abstract

1) Financial Results Management in Initial Public Offerings (IPOs) and Subsequent Performance of Shares

2) Objective of the Study: The aim of this research was to verify if the Brazilian companies that recently performed IPOs on the Stock Exchange managed their results, improving them in the periods near the launch and, consequently, presented a poor performance in the long term, due to reversals of accounting accruals related to management.
} 
3) Methodology / approach: A positive / quantitative research approach was used, having as main technique the estimation and analysis of the regression models proposed by Kothari, Leone and Wasley (2005) and the Dechow, Sloan and Sweeney (1995) to evaluate the possibility that companies may be managing their accounting results prior to IPOs.

4) Originality / Relevance: The Analysis implemented here is relevant because it aims to clarify for capital market investors whether firms tend to manage their results in order to obtain better stock prices, benefiting from a market failure linked to informational asymmetry between its (better informed) managers and potential investors, with worse information about the company.

5) Main Results: 92 IPOs occurred in Brazil were evaluated. As for the performance metrics analyzed, it could be inferred that managers apparently have been managing firms' results in order to improve these indicators in the moments prior to the launch of actions aiming at a positive market reaction. Finally, it was also observed that, for all subsequent periods analyzed (years $+1,+2$ and +3 ), the average return on IPO companies with lower levels of discretionary accruals were higher than the average return presented by IPO companies with higher levels of discretionary accruals.

6) Theoretical / Methodological Contributions: The work may show a better fit of the Kothari, Leone and Wasley (2005) Performance-Matching model compared to the traditional model of analysis from Dechow, Sloan and Sweeney (1995) for estimation and identification of earnings management practice in firms.

Keywords: Earnings Management, Economic and Financial Performance, Return on Shares, Accounting Accruals.

\section{Resumen}

\section{1) Gestión de resultados financieros en ofertas públicas iniciales (OPI) y rendimiento posterior de acciones}

2) Objetivo del estudio: El objetivo de esta investigación fue verificar si las empresas brasileñas que recientemente realizaron OPI en la Bolsa de Valores gestionaron sus resultados, mejorándolos en los períodos cercanos al lanzamiento y, en consecuencia, presentaron un mal desempeño a largo plazo. reversiones de devengos contables relacionados con la gestión.

3) Metodología / enfoque: se utilizó un enfoque de investigación positivo / cuantitativo, teniendo como técnica principal la estimación y el análisis de los modelos de regresión propuestos por Kothari, Leone y Wasley (2005) y el modelo de Dechow, Sloan y Sweeney (1995). para evaluar la posibilidad de que las empresas estén gestionando sus resultados contables antes de las OPI.

4) Originalidad / Relevancia: el análisis implementado aquí es relevante porque tiene como objetivo aclarar para los inversores del mercado de capitales si las empresas tienden a gestionar sus resultados para obtener mejores precios de las acciones, beneficiándose de una falla del mercado vinculada a asimetría informativa entre sus gerentes (mejor informados) y potenciales inversores, con peor información sobre la empresa.

5) Resultados principales: se evaluaron 92 OPI en Brasil. En cuanto a las métricas de desempeño analizadas, se podría inferir que los gerentes aparentemente han estado administrando los resultados de las empresas para mejorar estos indicadores en los momentos previos al lanzamiento de acciones destinadas a una reacción positiva del mercado. Finalmente, también se observó que, para todos los períodos posteriores analizados (años $+1,+2$ y +3 ), el rendimiento promedio de las compañías de OPI con niveles más bajos de acumulación 
discrecional fue mayor que el promedio. rentabilidad promedio presentada por las compañías de OPI con mayores niveles de acumulación discrecional.

6) Contribuciones teóricas / metodológicas: El trabajo puede mostrar un mejor ajuste del modelo Kothari, Leone y Wasley (2005) Performance-Matching en comparación con el modelo tradicional de análisis de Dechow, Sloan y Sweeney (1995).

Palabras clave: Gestión de ingresos, desempeño económico y financiero, retorno de acciones, devengos contables.

\section{Introdução}

Um assunto que, recentemente, tem despertado o interesse de acadêmicos, analistas, reguladores, investidores e outros profissionais ligados ao mercado de capitais, diz respeito à manipulação dos resultados nos relatórios contábil-financeiros que são reportados. Isto se deve ao fato de que os recentes colapsos de algumas grandes companhias terem sido, até certo ponto, “encobertos/mascarados” pelas manipulações nas demonstrações contábeis, levantando sérios questionamentos sobre a qualidade das informações financeiras reportadas e, também, sobre a efetividade das normas e padrões contábeis criados com o intuito de proteger os usuários que tomam suas decisões a partir dessas informações (Bispo, 2010).

O gerenciamento dos resultados apresentados nas demonstrações financeiras compromete a qualidade da informação contábil, podendo afetar a forma pela qual os investimentos são alocados entre empresas e entre países. Além disso, essa prática pode provocar colapsos no mercado como um todo, uma vez que, a contabilidade, como grande plataforma informacional é preponderante em grande parte das negociações envolvendo empresas e as demonstrações contábil-financeiras se destacam como principal meio de comunicação entre empresa e mercado (Martinez, 2001).

Neste âmbito, maior ênfase vem sendo dada recentemente à investigação dos efeitos que o gerenciamento de resultados acarreta para todos stakeholders das informações financeiras, principalmente o efeito destas práticas para os mercados de capitais, uma vez que, podem comprometer toda a alocação dos recursos. Estudos como o de Aharony, Lin e Loeb (1993), Teoh, Welch e Wong (1998), Teoh, Wong e Rao (1998), Paulo (2006), Zielinski (2013), Gioielli, Carvalho e Sampaio (2013) e Alhadab, Clacher e Keasey (2013) objetivaram pesquisar esse tipo de prática no contexto das Ofertas Públicas Iniciais. Eventos como os das empresas World.com enfatizam a grande necessidade de se compreender o gerenciamento de resultados, interesses, meios, consequências e demais dados importantes. Cabe ressaltar que o 
gerenciamento de resultados coloca em pauta a finalidade principal da contabilidade de servir como plataforma informacional.

Dado este contexto, a expectativa para este estudo é elucidar a possibilidade de que as empresas que se engajam em IPOs têm incentivos para aumentar seus resultados em exercícios que precedem e marcam o lançamento das ações, diminuindo esse incentivo em exercícios seguintes. Assim sendo, o problema que se procura elucidar diz respeito à seguinte questão de pesquisa:

As empresas brasileiras gerenciam seus resultados contábeis positivamente a fim de valorizar suas ações em períodos prévios a um IPO, originando uma performance econômicofinanceira fraca no longo prazo, fruto das reversões dos accruals relativos ao gerenciamento?

Estabelece-se, baseando-se no apresentado, que as hipóteses de pesquisa giram em torno dos incentivos para gerenciar resultados por parte dos gestores das empresas IPO. Neste sentido, para nortear a pesquisa, foram elaboradas as seguintes hipóteses:

\section{Hipótese 1: As empresas brasileiras que realizaram IPO recentemente gerenciaram} seus resultados nos períodos próximos (antecedentes ou que marcam) o IPO.

Pesquisas internacionais (Aharony, Lin e Loeb (1993), Teoh, Welch e Wong (1998), Zielinski (2013) e Alhadab, Clacher e Keasey (2013)) apontam evidências de gerenciamento de resultados envolvendo os accruals em períodos anteriores e que marcam o IPO.

Hipótese 2: As empresas que realizaram IPO com maiores acumulações discricionárias apresentaram melhor desempenho econômico-financeiro nos anos que precederam $e$ marcaram o lançamento das ações e baixa performance no longo prazo em função das reversões decorrentes do gerenciamento praticado. Apresentam ainda, no longo prazo, performance distinta e inferior ao de empresas que não gerenciaram seus resultados.

Martinez (2001) ressalta que existem evidências de que: i) os resultados contábilfinanceiros prévios às ofertas públicas são excepcionalmente favoráveis; ii) os resultados contábil-financeiros após o lançamento são de modo geral modestos nos anos seguintes à emissão; e iii) existe forte associação entre a extensão do gerenciamento de resultados e o desempenho subsequente da ação. Assim sendo, empresas com maiores acumulações têm pior desempenho no longo prazo. 
Hipótese 3: $O$ retorno das ações no longo prazo após o IPO das empresas que gerenciaram seus resultados contábeis de forma agressiva é inferior ao das empresas que não gerenciaram seus resultados, proveniente das reversões do gerenciamento de resultados praticado.

Teoh, Welch e Wong (1998), Teoh, Wong e Rao (1998), Singer (2007), Zielinski (2013), Gioielli, Carvalho e Sampaio (2013) e Alhadab, Clacher e Keasey (2013) apontam evidências de gerenciamento de resultados em períodos prévios ao IPO, contribuindo, assim, para o acréscimo nos lucros da empresa nestes períodos e para lucros e retorno das ações abaixo do previsto no longo prazo após o lançamento.

\section{Referencial teórico}

\subsection{Oferta Pública Inicial de Ações (Initial Public Offering - IPO)}

A retomada do lançamento de IPOs no mercado brasileiro de ações a partir de 2004 culminou em 2007 com a abertura de capital de 64 empresas, que, conjuntamente, captaram cerca de $\mathrm{R} \$ 55$ bilhões. Tal montante é excepcional tanto se comparado ao dos anos anteriores ou ao valor total de desembolsos do Banco Nacional do Desenvolvimento (BNDES), principal fonte de financiamento de longo prazo das grandes empresas brasileiras (Aldrighi et al, 2010). Entre 2002 e 2013, 155 empresas passaram a negociar suas ações na bolsa brasileira (Bovespa). Juntas, essas empresas captaram montante superior a R\$100 bilhões (BM\&FBOVESPA, 2014).

Existem algumas características marcantes do processo de abertura de capital que oferecem oportunidades e incentivos para gerenciar os lucros. Primeiro, há relativamente pouca informação disponível para os investidores a partir de fontes públicas sobre as empresas privadas fazendo com que os investidores confiem principalmente nas declarações contábilfinanceiras relatadas no prospecto. Teoh, Wong e Rao (1998) relata que quase não há cobertura da mídia nas empresas nos anos anteriores a oferta. Assim, o emitente e o subscritor podem ter um incentivo para reportar informações contábil-financeiras favoráveis no prospecto, ou melhor, os gestores têm um incentivo para gerenciar os resultados contábeis que serão reportados (Teoh, Wong e Rao, 1998). 


\subsection{Gerenciamento de Resultados Contábeis}

Os escândalos financeiros nos últimos anos fizeram com que a política de governança corporativa tenha se tornado um dos temas mais discutidos no mundo empresarial e acadêmico. Os trabalhos mais recentes reconhecem que os mecanismos de governança corporativa surgem como instrumentos para corrigir falhas existentes no mercado, devido aos conflitos de agência e a questões de assimetria informacional, não observada pela teoria da firma (Iudícibus e Lopes, 2004).

Atualmente, existe uma linha de pesquisa em contabilidade dedicada a investigar se gestores de empresas utilizam sua discricionariedade para influenciar os números contábeis com o objetivo de atender a interesses particulares, sua função de utilidade ou bem-estar. Em âmbito internacional, essa linha de pesquisa é denominada balance-sheet management (gerenciamento do balanço patrimonial) e earnings management (gerenciamento de resultados) (Ronen e Yaari, 2008).

Neste contexto, assim como nas pesquisas de Jones (1991), Teoh, Welch e Wong (1998), Teoh, Wong e Rao (1998), Healy e Wahlen (1999), Paulo (2006), Gioielli, Carvalho e Sampaio (2013) e Alhadab, Clacher e Keasey (2013) nesta investigação, procurou-se esclarecer um pouco mais sobre earnings management e sobre como impactam o processo de abertura de capital das firmas.

\section{Metodologia}

A metodologia utilizada na pesquisa é classificada quanto aos objetivos como descritiva, uma vez que, procura-se analisar e descrever o nível de accruals e o desempenho de empresas que realizaram IPO no Brasil. Tomou-se como base os dados até 2014 de forma que se pudesse avaliar o desempenho de carteiras formadas com ações dessas firmas participantes de IPO's até 3 anos pós abertura do capital. Quanto às estratégias de pesquisa, se classifica como documental e quantitativa, uma vez que, pretende-se através da análise dos demonstrativos contábil-financeiros das entidades, verificar se as mesmas gerenciam seus resultados contábeis usufruindo dos accruals em momentos que precedem ou marcam o lançamento das ações e se apresentam desempenho inferior no longo prazo fruto das reversões do gerenciamento. 
Os dados contábeis utilizados foram aqueles divulgados trimestralmente, disponíveis no sistema Economática®. Para análise estatística foi utilizado o software STATA®. Consideraram-se aqueles IPOs de empresas que disponibilizaram suas demonstrações financeiras de forma consecutiva em anos anteriores e posteriores ao lançamento.

A coleta dos dados compreendeu ainda os demonstrativos contábil-financeiros das empresas listadas na $[\mathrm{B}]^{3}$ e seus prospectos de IPOs, sendo obtidos dados nos sites da Comissão de Valores Mobiliários (CVM) e sites institucionais. Foram excluídas as ofertas realizadas por instituições financeiras, pois estas têm características, transações e controles diferenciados das empresas dos demais segmentos. Este padrão foi observado em trabalhos como os de Hochberg (2011) e Gioielli, Carvalho e Sampaio (2013).

\subsection{Métodos para Identificação dos Accruals Discricionários}

O gerenciamento das informações contábeis é considerado neste trabalho como um conjunto de práticas desenvolvidas pelos gestores, seja através das escolhas contábeis (EAM Accruals Earnings Management) ou alteração das atividades operacionais (reais) da empresa (ERM - Real Earnings Management), com o objetivo de interferir, intencionalmente, na informação reportada e, consequentemente, afetar a análise do desempenho da empresa ou influenciar as relações contratuais que dependam dos números contábeis.

Os accruals permitem que o resultado contábil reflita melhor o desempenho da empresa do que o fluxo de caixa. Surgem pela discrepância entre os movimentos nos fluxos de caixa (regime de caixa) e o reconhecimento contábil (regime da competência - em que as Demonstrações Financeiras são preparadas). Destarte, para estimar os accruals discricionários de uma empresa em um determinado período é necessário conhecer o valor dos accruals totais. Percebe-se que o valor dos accruals totais para uma empresa em determinado período será dado pela diferença entre o resultado contábil e o fluxo de caixa (equação 1).

\section{ACCRUALS TOTAIS = LUCRO LÍQUIDO - FLUXO DE CAIXA OPERACIONAL LÍQUIDO}

Contudo, os accruals totais podem ser estimados também pelo denominado enfoque do balanço (equação 2) que é o utilizado no presente trabalho. $\mathrm{O}$ enfoque do cálculo dos accruals totais com base nas mudanças em sucessivas contas patrimoniais está fundamentado no fato de que as mudanças no capital circulante líquido estão articuladas com os componentes de 
accruals de receitas e despesas na DRE (contas de resultado que participaram do resultado contábil, mas não das disponibilidades). Cabe ressaltar que todas as contas de resultado possuem contrapartida nas contas patrimoniais (Paulo, 2006).

$$
A C T_{i t}=\left(\left(\triangle A C_{i t}-\triangle D I S P_{i t}\right)-\left(\Delta P C_{i t}-\triangle F C P_{i t}\right)-\left(D E P_{i t}+A M O R T_{i t}\right)\right)
$$

Na equação 2, o nível de accruals totais $(A C T)$ de uma empresa será dado pela diferença entre a variação no ativo circulante $(\triangle A C)$ e nas disponibilidades $(\triangle D I S P)$ diminuído da diferença entre a variação do passivo circulante $(\triangle P C)$ e nos empréstimos e financiamentos de curto prazo $(\triangle F C P)$ diminuído da depreciação $(D E P)$ e amortização $(A M O R T)$ reconhecidas no período (acumulações não correntes).

Os modelos para detecção do gerenciamento de resultados contábeis têm se preocupado em identificar o nível de accruals não discricionários (normais, regulares para a empresa) em cada período de tempo. Dado que os accruals totais podem ser observados para uma empresa $i$ no período de tempo $t$ (enfoque do fluxo de caixa - eq. 1 ou do balanço patrimonial - eq. 2), obtém-se o nível de accruals discricionários - proxy do gerenciamento de resultados, pela diferença entre os accruals totais observados e os accruals não discricionários previstos pelos modelos. O nível de accruals discricionários é caracterizado assim como a parte não explicada dos accruals totais pelas variáveis dos modelos para detecção dos accruals não discricionários de uma empresa em determinado período de tempo.

A partir da hipótese de que é mais fácil para os gestores praticar a manipulação das informações contábeis através da rubrica de contas a receber do que através das vendas a vista, Dechow, Sloan e Sweeney (1995), propõem a incorporação, ao modelo de Jones (1991), da variável variação de contas a receber no período no qual se espera que o gerenciamento aconteça. Sendo assim, pode-se expressar a sugestão de Dechow, Sloan e Sweeney (1995) por meio da seguinte equação:

$$
\frac{A C T_{i t}}{A T_{i t-1}}=\hat{\alpha}_{i}\left(\frac{1}{A T_{i t-1}}\right)+\hat{\beta}_{1 i}\left(\frac{\Delta R E C_{i t}-\Delta C R_{i t}}{A T_{i t-1}}\right)+\hat{\beta}_{2 i}\left(\frac{A P_{i t}}{A T_{i t-1}}\right)+\varepsilon_{i t}
$$

Sendo que:

$$
\frac{A N D_{i t}}{A T_{i t-1}}=\alpha_{i}\left(\frac{1}{A T_{i t-1}}\right)+\beta_{1 i}\left(\frac{\Delta R E C_{i t}-\Delta C R_{i t}}{A T_{i t-1}}\right)+\beta_{2 i}\left(\frac{A P_{i t}}{A T_{i t-1}}\right)
$$

Em que:

$A C T_{i t}=$ accruals totais da empresa $i$ no período $t$; 
$A N D_{i t}=$ accruals não-discricionários da empresa $i$ no período $t$

$A T_{i t-1}=$ ativo total da empresa $i$ no período $t-1$;

$\Delta C R_{i t}=$ contas a receber da empresa $i$ no período $t$ menos o valor das contas a receber do período $t-1$;

$\Delta R E C_{i t}=$ receitas operacionais líquidas da empresa $i$ no período $t$ menos as receitas do período $t-1$

$A P_{i t}=$ ativo permanente da empresa $i$ no período $t$;

$\alpha_{i}, \beta_{1 i}$ e $\beta_{2 i}=$ parâmetros específicos para cada empresa;

$\hat{\alpha}_{i}, \hat{\beta}_{1 i}$ e $\hat{\beta}_{2 i}=$ coeficientes estimados na regressão; e

$\varepsilon_{i t}=$ termo de erro da regressão padronizado por $\operatorname{AT}_{i t-1 .}$.

Assim sendo, o modelo de Dechow, Sloan e Sweeney (1995) ou Jones Modificado segue as seguintes etapas para aferir o nível de accruals discricionários (proxy para o gerenciamento de resultados) para cada empresa:

Calcula-se os accruals totais:

$$
\frac{A C T_{i t}}{A T_{i t-1}}=\frac{\left(\triangle A C_{i t}-\triangle D I S P_{i t}\right)-\left(\triangle P C_{i t}-\triangle F C P_{i t}\right)-\left(D E P_{i t}+A M O R T_{i t}\right)}{A T_{i t-1}}
$$

Em seguida, após a mensuração dos accruals totais deve-se utilizar os coeficientes estimados $\left(\hat{\alpha}_{i}, \hat{\beta}_{1 i}\right.$ e $\left.\hat{\beta}_{2 i}\right)$ na equação (3) para a mensuração dos accruals não discricionários, por meio da seguinte regressão:

$$
\frac{A C T_{i t}}{A T_{i t-1}}=\hat{\alpha}_{i}\left(\frac{1}{A T_{i t-1}}\right)+\hat{\beta}_{1 i}\left(\frac{\Delta R E C_{i t}-\Delta C R_{i t}}{A T_{i t-1}}\right)+\hat{\beta}_{2 i}\left(\frac{A P_{i t}}{A T_{i t-1}}\right)+\varepsilon_{i t}
$$

Sendo que:

$$
\frac{A N D_{i t}}{A T_{i t-1}}=\alpha_{i}\left(\frac{1}{A T_{i t-1}}\right)+\beta_{1 i}\left(\frac{\Delta R E C_{i t}-\Delta C R_{i t}}{A T_{i t-1}}\right)+\beta_{2 i}\left(\frac{A P_{i t}}{A T_{i t-1}}\right)
$$

A partir daí, o resultado da diferença entre os accruals totais (ACT) e os accruals não discricionários (AND) resultará na estimativa do valor dos accruals discricionários (AD). Ou seja, a parte dos accruals totais (variável dependente) não explicada pelos accruals não discricionários (regulares/normais para a empresa), o termo de erro $\left(\varepsilon_{i t}\right)$, resultará na estimativa do valor dos accruals discricionários (proxy para o gerenciamento de resultados). Pode-se concluir então que:

$$
\frac{A D_{i t}}{A T_{i t-1}}=\frac{A C T_{i t}}{A T_{i t-1}}-\frac{A N D_{i t}}{A T_{i t-1}}
$$


Assim, na versão modificada do modelo de Jones (1991), tem-se que:

$$
A D_{i t}=\varepsilon_{i t}
$$

Em que:

$A D_{i t}=$ accruals discricionários da empresa $i$ no período $t ;$ e

$\mathcal{E}_{i t}=$ termo de erro da equação 6 (padronizado pelo ativo total do período anterior).

É importante destacar ainda que, objetivando a realização de inferências mais robustas, o modelo desenvolvido por Kothari, Leone e Wasley (2005) (Modelo de PerformanceMatching (2005)) que incorpora a performance das empresas no cálculo dos accruals foi também utilizado neste trabalho paralelamente ao Modelo de Jones Modificado (2005) desenvolvido por Dechow, Sloan e Sweeney (1995).

Neste âmbito, Kothari, Leone e Wasley (2005) enfatizam que os accruals discricionários calculados com base nos modelos de Jones (1991) e Jones Modificado (1995) desenvolvido por Dechow, Sloan e Sweeney (1995) seriam melhor especificados caso os modelos incorporassem variável que controlasse o desempenho das empresas que compõe a amostra da pesquisa, pois, segundo os primeiros, os accruals discricionários calculados com base nos modelos de Jones (1991) e Jones Modificado (1995) são significativamente influenciados pelo desempenho da empresa, principalmente se essa performance for anormal.

Corroborando, como a maioria das investigações acerca do gerenciamento de resultados contábeis trata de eventos em que empresas de distintos setores e tamanho estão envolvidas, variáveis como a performance das empresas pode afetar a estimação do gerenciamento de resultados por que os accruals não discricionários (ajustes normais para as empresas) poderão ser classificados erroneamente como discricionários quando essa performance for anormal (sofrer significativas variações positivas ou negativas).

Entretanto, Kothari, Leone e Wasley (2005) elucidam que uma forma de controle para a influência do desempenho da empresa na estimativa das acumulações discricionárias é desenvolver melhores modelos que são imunes aos efeitos do desempenho. Neste espírito, os autores incorporam ao Modelo de Jones Modificado (1995) o retorno sobre os ativos do período anterior como proxy do desempenho objetivando melhor classificação dos accruals buscando controlar a influência do desempenho da empresa na estimação das acumulações discricionárias com o desenvolvimento de um modelo capaz de captar os efeitos do desempenho.

Destarte, a escolha do Retorno sobre os ativos (ROA) como proxy de desempenho é lógico, porque os ativos são normalmente usados como um deflator nos modelos de acréscimos discricionários e o ROA, na essência, se caracteriza como um índice padronizado pelo ativo das 
empresas. Já a explicação para a utilização do ROA do período passado (taxa defasada de retorno sobre os ativos) seria para coincidir com o crescimento das receitas no passado, variável já embutida nos principais modelos relacionados ao tema gerenciamento de resultados. No entanto, a incorporação desta variável serve para melhor aferir outros fatores que contribuem para o processo de geração de ajustes regulares da empresa (susceptíveis de afetar a magnitude de acréscimos não discricionários, assim como as receitas e o ativo permanente). Sendo assim, segue a equação do Modelo de Kothari, Leone, Wasley (2005):

$$
\frac{A N D_{i t}}{A T_{i t-1}}=\alpha_{0 i}+\beta_{1 i}\left(\frac{1}{A T_{i t-1}}\right)+\beta_{2 i}\left(\frac{\Delta R E C_{i t}-\Delta C R_{i t}}{A T_{i t-1}}\right)+\beta_{3 i}\left(\frac{A P_{i t}}{A T_{i t-1}}\right)+\beta_{4 i}\left(R O A_{i t-1}\right)
$$

Em que:

$A N D_{i t}=$ accruals não discricionários padronizados pelo ativo total de $t-1$;

$\Delta C R_{i t}=$ contas a receber da empresa $i$ no período $t$ menos o valor das contas a receber do período $t-1$;

$\triangle R E C_{i t}=$ receitas operacionais líquidas da empresa $i$ no período $t$ menos as receitas do período $t-1$

$A P_{i t}=$ ativo permanente da empresa $i$ no período $t$;

$R O A_{i t-1}=$ retorno sobre o ativo do período $t-1$;

$\varepsilon_{i t}=$ termo de erro da regressão;

$\alpha_{0 i}, \beta_{1 i}, \beta_{2 i}, \beta_{3 i}$ e $\beta_{4 i}=$ coeficientes estimados na regressão; e

$\mathrm{AT}_{i t-1}=$ ativo total da empresa $i$ do período $t-1$.

\subsection{Métricas utilizadas para comparação do Desempenho Econômico-Financeiro}

Apesar da existência de enorme variedade de índices, este trabalho restringirá à análise daqueles considerados essenciais e amplamente utilizados pela academia nacional e internacional em prol da comparação entre o desempenho das entidades antes e após o IPO e também comparação entre o desempenho de empresas gerenciadoras e não gerenciadoras.

Os índices utilizados foram: Retorno sobre o Ativo (ROA); Margem do EBITDA; Valor Patrimonial da Ação (VPA); Lucro por Ação (LPA); Preço sobre Lucro por Ação (P/L), e Dividendos por Ação (DPA). 
Posteriormente a apuração dos indicadores será realizado o teste $t$ para diferença entre médias aritméticas. Por meio deste teste buscará verificar se as médias das duas populações (empresas que gerenciaram agressivamente seus resultados e empresas que não gerenciaram seus resultados) são significativamente diferentes entre si.

Serão analisados, neste contexto, os resultados médios apresentados pelos diferentes grupos de empresas $i$ nos períodos $t$. Para a análise do desempenho das empresas IPO, antes e após o lançamento, serão analisados (ano-1; ano 0 ; $\mathrm{ano}_{+1}, \mathrm{ano}_{+2}$ e $\left.\mathrm{ano}_{+3}\right)$. Para comparação do desempenho no longo prazo (período que se espera encontrar resultados mais baixos para as empresas que supostamente gerenciaram seus resultados em função das reversões do gerenciamento praticado quando do lançamento das ações) entre empresas gerenciadoras (tercil 3) e não gerenciadoras (tercil 1) serão analisados $\left(\mathrm{ano}_{+1}, \mathrm{ano}_{+2} \mathrm{e} \mathrm{ano}_{+3}\right)$.

\subsection{Método para comparação do Desempenho de Carteiras (Retorno das Ações) das empresas que realizaram IPO}

Espera-se que o retorno das ações no longo prazo após o IPO das empresas que gerenciaram seus resultados contábeis de forma agressiva seja inferior ao das empresas que não gerenciaram seus resultados. A tendência é que as empresas que gerenciaram agressivamente seus resultados (classificadas no tercil 3) apresentem desempenho mais fraco no longo prazo no que tange retorno das ações, proveniente das reversões do gerenciamento de resultados praticado.

Assim sendo, análises serão realizadas com os retornos das ações (Equação 11), assim como nas pesquisas de Costa Jr. e Neves (2000) e Galdino (2010). Estes dados foram obtidos por meio de cotações do Economática ${ }^{\circledR}$. Neste contexto, os retornos para a ação $i$ serão obtidos através da equação:

$$
R_{i t}=\left(\frac{P_{t I P O+n}-P_{t I P O}}{P_{t I P O}}\right) x 100
$$

Em que:

$R_{i t}=$ Retorno da ação $i$ no período $t$;

$P_{t I P O}+n=$ Cotação de fechamento da ação $i$ no período $t(t+1 ; t+2 e t+3)$;

$P_{t I P O}=$ Cotação de fechamento/Preço de oferta da ação $i$ no dia da oferta pública inicial. 


\section{Análise de resultados \\ 4.1 Análise do Gerenciamento de Resultados}

Neste tópico, considera-se a estimação dos accruals discricionários pelo modelo de Jones Modificado (1995) e pelo modelo de Performance-Matching (2005), os quais explicam o montante dos accruals não discricionários pela variação na Receita deduzida das contas a receber e nos investimentos em Ativos Permanentes. O modelo de Performance-Matching inclui ainda a variável ROA, objetivando captar o efeito da performance na formação dos accruals não discricionários.

Assim sendo, foram iniciados os procedimentos metodológicos para verificar a hipótese (H1) deste trabalho onde espera-se que as empresas que realizaram IPO apresentem maior nível de accruals discricionários em períodos que antecedem e marcam o IPO (ano-1, ano 0 e ano +1$)$ do que em períodos posteriores ao lançamento $\left(\mathrm{ano}_{+2}\right.$ e $\left.\mathrm{ano}_{+3}\right)$ sinalizando para o fato de que estas empresas gerenciaram seus resultados nos períodos próximos ao IPO.

Para dar continuidade ao estudo, foram estimadas cinquenta e uma regressões para Cortes Transversais utilizando todas as observações/trimestre das empresas que formam o grupo de controle, composto pelas empresas listadas na BM\&FBovespa excluindo as empresas que realizaram IPOs entre 2002 e 2010. As empresas que realizaram Oferta Subsequente de Ações (SEO) no mesmo período também foram excluídas em função do objetivo para gerenciar resultados que também pode ser verificado para estas empresas. Além disso, as empresas do setor econômico Finanças e Outros (segundo classificação setorial da Bovespa) que contém características econômico-financeiras distintas das empresas dos demais segmentos também foram excluídas. Contudo, o grupo de controle é formado por 187 empresas listadas na BM\&FBovespa.

Após a coleta dos dados para estas empresas no período de 2001 a 2013 foram realizadas regressões objetivando elucidar quais os coeficientes normais dos modelos utilizados para cada período analisado (anos $-1,0,+1,+2$ e +3 ). O primeiro trimestre de 2001 só serve de base para cálculo das variáveis que compõem os modelos utilizados, já que os mesmos incorporam a variação das variáveis entre o período $t$ e o período $t-1$ para cálculo dos accruals do período t. Assim sendo, foram realizadas 3 regressões (em 2001) e 4 regressões (para os anos de 2002 a 2013) totalizando 51 regressões.

Para todos os períodos analisados foi obtido melhoras no que tange as regressões realizadas para o modelo de Jones Modificado (1995) e o modelo de Performance-Matching 
(2005). Em todos os 51 trimestres o $\mathrm{R}^{2}$ e $\mathrm{R}^{2}$ Ajustado das regressões foram maiores para o modelo de Performance-Matching (2005). Também não foram encontrados problemas econométricos relacionados a multicolinearidade, autocorrelação e heterocedasticidade.

Foram realizados o teste VIF objetivando detectar problemas relacionados a multicolinearidade entre as variáveis, o teste de Breusch-Pagan para problemas relacionados a heterocedasticidade dos resíduos e o teste de Breusch-Godfrey para problemas relacionados a autocorrelação entre os resíduos. O teste RESET também foi realizado para a correta especificação do modelo. Não foram encontrados problemas econométricos que comprometessem os resultados obtidos com as regressões realizadas para o grupo de controle que é formado por 187 empresas listadas na BM\&FBovespa).

Tabela 1. Estatísticas descritivas e testes de diferença de médias do nível de gerenciamento de resultados nas fases do IPO (AD em \% dos ativos totais do período anterior).

\begin{tabular}{|c|c|c|c|c|c|c|c|c|}
\hline \multirow{2}{*}{ Modelo } & Ano -1 & Ano 0 & Ano +1 & Ano +2 & $\begin{array}{c}\text { Ano } \\
+3 \\
\end{array}$ & \multirow{2}{*}{ Diferença } & \multirow{2}{*}{$\begin{array}{c}\text { Prob } \\
(T>t)\end{array}$} & \multirow{2}{*}{ Estat. $t$} \\
\hline & $\begin{array}{l}\text { Pré- } \\
\text { IPO }\end{array}$ & IPO & $\begin{array}{l}\text { Pós- } \\
\text { IPO }\end{array}$ & $\begin{array}{l}\text { Pós- } \\
\text { IPO }\end{array}$ & $\begin{array}{l}\text { Pós- } \\
\text { IPO }\end{array}$ & & & \\
\hline Jones Modificado & $7.96 \%$ & $14.23 \%$ & $5.64 \%$ & $1.20 \%$ & $1.60 \%$ & & & \\
\hline Pré-IPO X IPO & $7.96 \%$ & $14.23 \%$ & & & & $-6.27 \%$ & 0.1764 & -1.09 \\
\hline Pré-IPO X Pós-IPO & $7.96 \%$ & & \multicolumn{3}{|c|}{$2.81 \%$} & $5.15 \%$ & $0.0002 *$ & 5.15 \\
\hline IPO X Pós-IPO & & $14.23 \%$ & \multicolumn{3}{|c|}{$2.81 \%$} & $11.42 \%$ & $0.0000 *$ & 8.76 \\
\hline $\begin{array}{c}\text { Pré-IPO + IPO X } \\
\text { Pós-IPO } \\
\end{array}$ & \multicolumn{2}{|c|}{$11.54 \%$} & \multicolumn{3}{|c|}{$2.81 \%$} & $8.73 \%$ & $0.0032 *$ & 3.37 \\
\hline $\begin{array}{c}\text { Pós-IPO (1) X Pós- } \\
\text { IPO (2 e 3) }\end{array}$ & & & $5.64 \%$ & \multicolumn{2}{|c|}{$1.40 \%$} & $4.24 \%$ & $0.0075^{*}$ & 2.37 \\
\hline $\begin{array}{c}\text { Performance } \\
\text { Matching }\end{array}$ & $10.50 \%$ & $13.28 \%$ & $4.02 \%$ & $0.08 \%$ & $2.02 \%$ & & & \\
\hline Pré-IPO X IPO & $10.50 \%$ & $13.28 \%$ & & & & $-2.78 \%$ & 0.3050 & -0.56 \\
\hline Pré-IPO X Pós-IPO & $10.50 \%$ & & & $2.04 \%$ & & $8.46 \%$ & $0.0000 *$ & 6.02 \\
\hline IPO X Pós-IPO & & $13.28 \%$ & & $2.04 \%$ & & $11.24 \%$ & $0.0000 *$ & 8.10 \\
\hline $\begin{array}{c}\text { Pré-IPO +IPOX } \\
\text { Pós-IPO } \\
\end{array}$ & 12 & & & $2.04 \%$ & & $10.04 \%$ & $0.0016^{*}$ & 3.74 \\
\hline $\begin{array}{c}\text { Pós-IPO (1) X Pós- } \\
\text { IPO (2 e 3) }\end{array}$ & & & $4.02 \%$ & & & $2.97 \%$ & $\begin{array}{l}0.0819 * \\
*\end{array}$ & 1.47 \\
\hline
\end{tabular}

(*) e (**) Denota significância estatística ao nível de 5\% e 10\%, respectivamente.

Fonte: Resultados da pesquisa.

Na Tabela 1 observam-se os níveis médios de accruals discricionários apurados para as empresas IPO nas diferentes fases estudadas (Anos -1, 0, +1, +2 e +3). Observa-se que, em média, as acumulações discricionárias são positivas e relevantes no período que engloba os três anos imediatamente ao redor do IPO (anos $-1,0$ e +1$)$, o que corrobora com os resultados obtidos por Teoh, Welch e Wong (1998). Gioielli, Carvalho e Sampaio (2013) e Alhadab, Clacher e Keasey (2013) também verificaram o mesmo padrão observado neste trabalho com 
elevados níveis de accruals discricionários para as empresas IPO nos períodos que imediatamente antecedem, marcam e posteriores ao IPO.

No ano +1 , que compreende o período pré-expiração da cláusula lock-up, quando também há incentivos para a prática de gerenciamento, o nível médio das acumulações discricionárias, é positivo e também muito diferente dos patamares médios identificados nas fases com menores incentivos (anos $+2 \mathrm{e}+3$ ). Este resultado traz evidências de que, no caso brasileiro, a busca por maior valorização dos papéis para a venda das ações dos insiders logo após a expiração da cláusula lock-up também parece ser uma das motivações dos administradores para gerenciar os resultados contábeis.

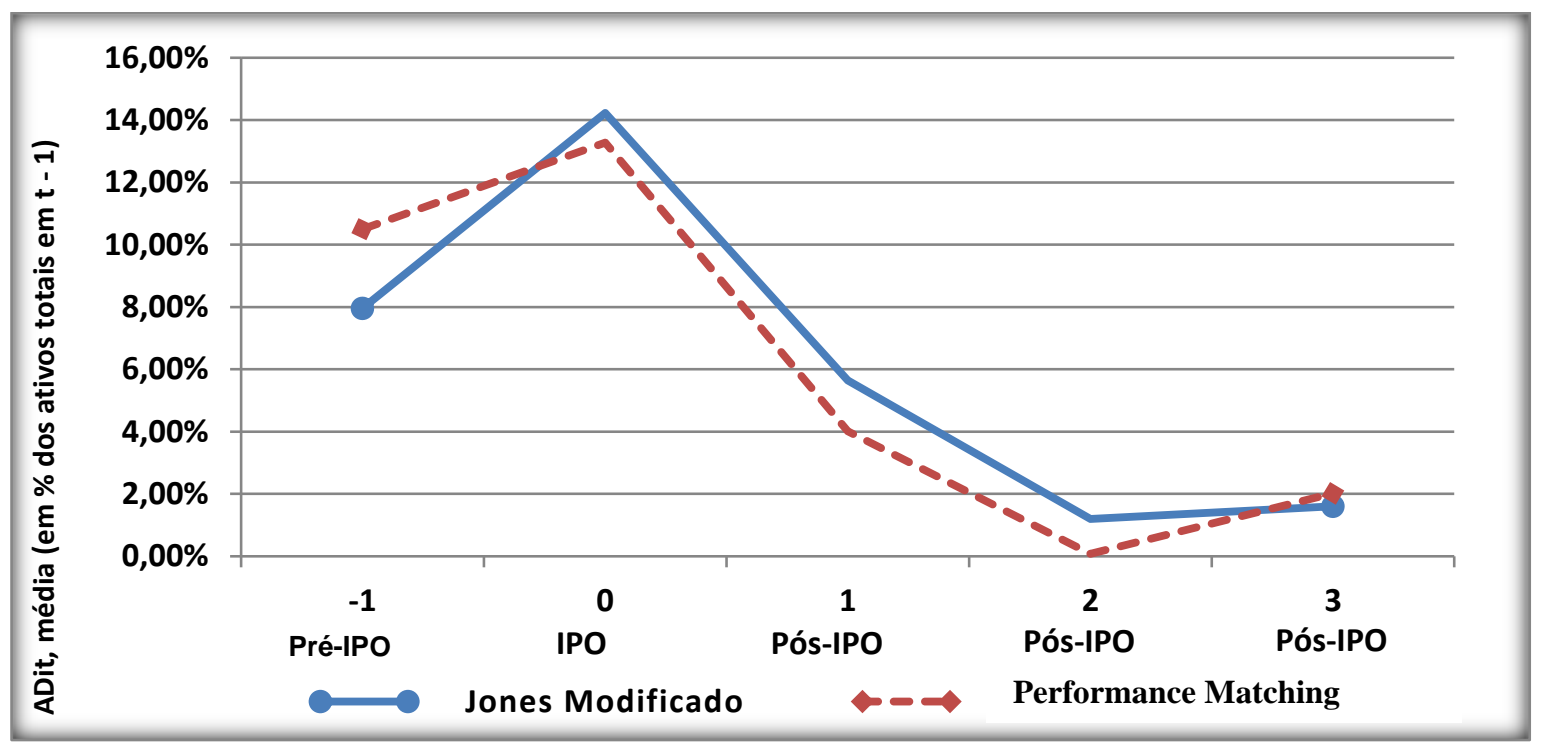

Gráfico 1. Nível médio de acumulações discricionárias $\left(A D_{i, t}\right)$ por fases das empresas IPO. Fonte: Resultados da pesquisa.

No Gráfico 1, é melhor elucidado como o objetivo para gerenciar resultados é forte nos períodos que antecedem, marcam e imediatamente posteriores à oferta pública inicial de ações. A distribuição do valor médio dos accruals evidencia um alto nível de gerenciamento no intervalo imediatamente ao redor da data do IPO (anos -1, 0 e +1$)$. Este comportamento sugere que os incentivos para gerenciar resultados são altos impulsionando positivos e relevantes níveis de accruals discricionários quando da oferta pública de ações.

Ou seja, há fortes indícios de que as empresas brasileiras que realizaram IPO no Brasil pós 2002 gerenciaram seus resultados nos períodos próximos (antecedentes e que marcam) o IPO. 


\subsection{Análise das Métricas para comparação do Desempenho Econômico-Financeiro}

Objetivando comparar os resultados obtidos pelas empresas, realizou-se a análise de indicadores de desempenho econômico-financeiros antes e depois do IPO (Tabela 2). Inicialmente, esperava-se que, em média, o desempenho econômico-financeiro fosse maior nos anos que antecedem e marcam o IPO (ano-1 e ano0), comparativamente com os anos $+1,+2$ e +3 , visto que existe a tendência dos gestores elevarem os lucros na intenção de transparecer ao mercado melhor imagem econômico-financeira da empresa quando do lançamento das ações.

Depois de analisados todos os resultados relacionados às métricas de performance das empresas IPO, encontraram-se evidências significativas para não rejeitar a hipótese $(\mathrm{H} 2)$ de que as companhias que realizaram IPO apresentaram melhor desempenho econômico-financeiro nos anos que precederam e marcaram a oferta pública inicial de ações. Isso foi inferido a partir do teste $t$ para a diferença entre as médias antes, durante e depois do IPO para os indicadores de ROA, Margem do EBITDA, LPA e P/L. Todos estes indicadores demonstraram maiores médias nos períodos que antecedem e marcam o lançamento das ações do que em períodos posteriores, como pôde ser observado na Tabela 2.

Entretanto, os indicadores de VPA e DPA não apresentaram maiores valores nos períodos que marcam o IPO e sim nos períodos posteriores ao lançamento. Quanto ao comportamento das métricas VPA e DPA, cabe ressaltar que, as empresas IPO se caracterizam como pequenas empresas em busca de oportunidades de crescimento sem poder para remunerar seus sócios. 
Tabela 2. Estatísticas descritivas das métricas de performance das empresas IPO por fases.

\begin{tabular}{|c|c|c|c|c|c|c|c|c|}
\hline \multirow{2}{*}{$\begin{array}{c}\text { Métricas de } \\
\text { Performance }\end{array}$} & Ano -1 & Ano 0 & Ano +1 & Ano +2 & Ano +3 & \multirow{2}{*}{ Diferença } & \multirow{2}{*}{$\begin{array}{c}\text { Prob } \\
(T>t)\end{array}$} & \multirow{2}{*}{ Estatística $t$} \\
\hline & Pré-IPO & IPO & Pós- IPO & Pós-IPO & Pós-IPO & & & \\
\hline$R O A$ & $7.42 \%$ & $7.89 \%$ & $3.46 \%$ & $3.20 \%$ & $2.97 \%$ & & & \\
\hline $\begin{array}{c}\text { Pré-IPO X Pós- } \\
\text { IPO }\end{array}$ & $7.42 \%$ & & \multicolumn{3}{|c|}{$3.21 \%$} & $4.21 \%$ & $0.0000^{*}$ & 6.41 \\
\hline IPO X Pós-IPO & & $7.89 \%$ & \multicolumn{3}{|c|}{$3.21 \%$} & $4.68 \%$ & $0.0000^{*}$ & 6.89 \\
\hline $\begin{array}{c}\text { Pré-IPO + IPO } \\
\text { X Pós-IPO }\end{array}$ & \multicolumn{2}{|c|}{$7.66 \%$} & \multicolumn{3}{|c|}{$3.21 \%$} & $4.45 \%$ & $0.0000^{*}$ & 5.99 \\
\hline $\begin{array}{c}\text { MARGEM DO } \\
\text { EBTIDA }\end{array}$ & $19.07 \%$ & $18.98 \%$ & $15.30 \%$ & $16.34 \%$ & $16.53 \%$ & & & \\
\hline $\begin{array}{c}\text { Pré-IPO X Pós- } \\
\text { IPO }\end{array}$ & $19.07 \%$ & & & $16.06 \%$ & & $3.01 \%$ & $0.0383 *$ & 1.77 \\
\hline IPO X Pós-IPO & & $18.98 \%$ & & $16.06 \%$ & & $2.92 \%$ & $0.0443 *$ & 1.71 \\
\hline $\begin{array}{c}\text { Pré-IPO + IPO } \\
\text { X Pós-IPO }\end{array}$ & \multicolumn{2}{|c|}{$19.46 \%$} & \multicolumn{3}{|c|}{$16.06 \%$} & $3.40 \%$ & $0.0710 * *$ & 1.47 \\
\hline$V P A$ & - & 7.65 & 7.63 & 8.19 & 8.38 & & & \\
\hline IPO X Pós-IPO & - & 7.65 & \multicolumn{3}{|c|}{8.07} & -0.42 & 0.3359 & -0.42 \\
\hline$L P A$ & - & 0.85 & 0.13 & 0.23 & 0.79 & & & \\
\hline IPO X Pós-IPO & - & 0.85 & \multicolumn{3}{|c|}{0.38} & 0.47 & $0.0023 *$ & 2.84 \\
\hline$P / L$ & - & 29.27 & 20.05 & 14.19 & 18.14 & & & \\
\hline IPO X Pós-IPO & - & 29.27 & \multicolumn{3}{|c|}{17.46} & 11.81 & $0.0002 *$ & 3.54 \\
\hline$D P A$ & - & 0.08 & 0.23 & 0.33 & 0.27 & & & \\
\hline IPO X Pós-IPO & - & 0.08 & \multicolumn{3}{|c|}{0.28} & -0.20 & $0.0000^{*}$ & -5.32 \\
\hline
\end{tabular}

$(*)$ e (**) Denota significância estatística ao nível de 5\% e 10\%, respectivamente.

Fonte: Resultados da Pesquisa.

Destarte, a partir dos resultados obtidos para todas as métricas de performance relacionadas, pode se inferir que os gestores podem estar gerenciando seus resultados no intuito de melhorar estes indicadores nos momentos que antecedem e marcam o lançamento das ações objetivando reação positiva do mercado, ou seja, ação oportunista para gerenciar resultados contábeis nos anos que antecederam e marcaram o IPO.

\subsection{Formação dos Tercis}

Os accruals discricionários estimados foram agrupados por período e por empresa, sendo classificados em ordem crescente no período estudado, no intuito de quantificar o grau de discricionariedade das empresas que compõem a amostra da pesquisa, assim como na pesquisa de Teoh, Welch e Wong (1998). Por conseguinte, os valores assumidos pelo termo de erro (parte dos accruals totais não explicada pelos accruals não discricionários) foram distribuídos 
em três níveis (tercis) de intensidade de gerenciamento (níveis de accruals discricionários). Os tercis foram formados pela média dos accruals discricionários apurados nos anos $-1,0$ e +1 (11 trimestres) - (período crítico para a prática do gerenciamento de resultados das empresas IPO).

Cabe destacar que, nesta pesquisa, analisam-se os incentivos relacionados ao IPO, sendo, portanto, investigado se as empresas gerenciaram positivamente seus resultados em períodos prévios e que marcam o IPO. Portanto, empresas com acumulações discricionárias positivas altas (classificadas no tercil 3) serão caracterizadas como empresas que gerenciaram agressivamente seus resultados e empresas com menores níveis de accruals discricionários (classificadas no tercil 1), serão consideradas como empresas não gerenciadoras. Na Tabela 3 observa-se a distição entre o nível médio de accruals discricionários para os tercis 1,2 e 3 . As médias dos accruals discricionários dos tercis 1, 2 e 3 foram estatisticamente diferentes tanto para o Modelo de Jones Modificado quanto para o Modelo de Performance-Matching.

Tabela 3. Estatística descritiva e diferença de médias do nível de AD em tercis.

\begin{tabular}{|c|c|c|c|c|c|c|}
\hline Modelo & Tercil 1 & Tercil 2 & Tercil 3 & Diferença & $\begin{array}{c}\text { Prob } \\
(T>t)\end{array}$ & $\begin{array}{c}\text { Estatística } \\
t\end{array}$ \\
\hline \multicolumn{7}{|l|}{ Jones Modificado } \\
\hline Média & $1.50 \%$ & $9.60 \%$ & $19.60 \%$ & & & \\
\hline Tercil 1 X Tercil 2 & $1.50 \%$ & $9.60 \%$ & & $-8.10 \%$ & $0.0000 *$ & -7.84 \\
\hline Tercil 1 X Tercil 3 & $1.50 \%$ & & $19.60 \%$ & $-18.10 \%$ & $0.0000^{*}$ & -9.80 \\
\hline Tercil 2 X Tercil 3 & & $9.60 \%$ & $19.60 \%$ & $-10.00 \%$ & $0.0000 *$ & -4.96 \\
\hline \multicolumn{7}{|l|}{ Performance Matching } \\
\hline Média & $0.20 \%$ & $7.80 \%$ & $20.50 \%$ & & & \\
\hline Tercil 1 X Tercil 2 & $0.20 \%$ & $7.80 \%$ & & $-7.60 \%$ & $0.0000^{*}$ & -9.84 \\
\hline Tercil 1 X Tercil 3 & $0.20 \%$ & & $20.50 \%$ & $-20.30 \%$ & $0.0000^{*}$ & -13.85 \\
\hline Tercil 2 X Tercil 3 & & $7.80 \%$ & $20.50 \%$ & $-12.70 \%$ & $0.0000 *$ & -9.16 \\
\hline
\end{tabular}

(*) e (**) Denota significância estatística ao nível de 5\% e 10\%, respectivamente.

Fonte: Resultados da pesquisa.

\subsection{Análise da Performance entre as Empresas dos Tercis 1 e 3}

Posteriormente, foram realizados testes para verificar se as médias das métricas de performance entre os tercis são estatisticamente distintas. Foram analisados o ROA, a Margem do EBTIDA, o LPA e o P/L.

O padrão observado para as métricas de performance corrobora com a hipótese $(\mathrm{H} 2)$ da pesquisa, uma vez que, nos períodos posteriores ao IPO as empresas classificadas no tercil 3 apresentaram desempenho mais fraco do que as empresas classificadas no tercil 1, o que pode 
ter sido ocasionado em função das reversões dos accruals discricionários que foram mais elevados para as empresas do tercil 3, nos anos que antecederam e marcaram o IPO.

Destarte, pode-se considerar que, no geral, os resultados corroboram com as hipóteses da pesquisa e com os resultados de trabalhos nacionais e internacionais (Paulo (2006), Teoh, Welch e Wong (1998) e Gioielli, Carvalho e Sampaio (2013)), como observa-se na Tabela 4.

Tabela 4: Estatísticas descritivas das Métricas de Performance dos tercis 1 e 3 do IPO

\begin{tabular}{|c|c|c|c|c|c|}
\hline $\begin{array}{c}\text { Métricas de } \\
\text { Performance }\end{array}$ & Ano -1 & Ano 0 & Ano +1 & Ano +2 & Ano +3 \\
\hline$R O A$ & $\begin{array}{l}\text { Pré- } \\
\text { IPO }\end{array}$ & IPO & Pós-IPO & $\begin{array}{l}\text { Pós- } \\
\text { IPO }\end{array}$ & $\begin{array}{l}\text { Pós- } \\
\text { IPO }\end{array}$ \\
\hline Tercil 1 & $6.22 \%$ & $6.56 \%$ & $7.94 \%$ & $7.67 \%$ & $6.78 \%$ \\
\hline Tercil 3 & $8.53 \%$ & $8.40 \%$ & $0.49 \%$ & $1.72 \%$ & $0.64 \%$ \\
\hline Diferença & $-2.31 \%$ & $-1.84 \%$ & $7.45 \%$ & $5.95 \%$ & $6.14 \%$ \\
\hline $\operatorname{Prob}(T>t)$ & 0.1832 & 0.2407 & $0.0011 *$ & 0.0018* & $0.0037 *$ \\
\hline Estatística $t$ & -0.9106 & -0.7087 & 3.211 & 30.291 & 27.805 \\
\hline MgEBTIDA & $\begin{array}{l}\text { Pré- } \\
\text { IPO }\end{array}$ & IPO & Pós-IPO & $\begin{array}{l}\text { Pós- } \\
\text { IPO }\end{array}$ & $\begin{array}{l}\text { Pós- } \\
\text { IPO }\end{array}$ \\
\hline Tercil 1 & $18.49 \%$ & $21.58 \%$ & $16.50 \%$ & $26.57 \%$ & $28.50 \%$ \\
\hline Tercil 3 & $16.21 \%$ & $16.20 \%$ & $10.11 \%$ & $11.29 \%$ & $8.63 \%$ \\
\hline Diferença & $2.28 \%$ & $5.38 \%$ & $6.39 \%$ & $15.28 \%$ & $19.87 \%$ \\
\hline $\operatorname{Prob}(T>t)$ & 0.3477 & 0.2013 & 0.2098 & $0.0108 *$ & $0.0038^{*}$ \\
\hline Estatística $t$ & -0.3937 & 0.8434 & 0.8134 & 23.682 & 27.725 \\
\hline$L P A$ & $\begin{array}{l}\text { Pré- } \\
\text { IPO }\end{array}$ & IPO & Pós-IPO & $\begin{array}{l}\text { Pós- } \\
\text { IPO }\end{array}$ & $\begin{array}{l}\text { Pós- } \\
\text { IPO }\end{array}$ \\
\hline Tercil 1 & - & 0.63 & 0.56 & 0.67 & 1.23 \\
\hline Tercil 3 & - & 0.72 & -0.69 & -0.20 & -0.01 \\
\hline Diferença & - & -0.09 & 1.25 & 0.87 & 1.24 \\
\hline $\operatorname{Prob}(T>t)$ & - & 0.3666 & $0.0562 * *$ & $0.0221 *$ & $0.0048 *$ \\
\hline Estatística $t$ & - & -0.3424 & 16.126 & \begin{tabular}{|l|}
20.601 \\
\end{tabular} & 26.889 \\
\hline$P / L$ & $\begin{array}{l}\text { Pré- } \\
\text { IPO }\end{array}$ & IPO & Pós-IPO & $\begin{array}{l}\text { Pós- } \\
\text { IPO }\end{array}$ & $\begin{array}{l}\text { Pós- } \\
\text { IPO }\end{array}$ \\
\hline Tercil 1 & - & 4.88 & 28.64 & 25.15 & 19.07 \\
\hline Tercil 3 & - & 38.85 & 22.19 & 10.49 & 23.71 \\
\hline Diferença & - & -33.97 & 6.45 & 14.66 & -4.64 \\
\hline $\operatorname{Prob}(T>t)$ & - & $0.0028 *$ & 0.3053 & 0.1320 & 0.3147 \\
\hline Estatística $t$ & - & -28.931 & 0.5122 & 11.296 & -0.4854 \\
\hline
\end{tabular}

(*) e (**) Denota significância estatística ao nível de 5\% e 10\%, respectivamente. Fonte: Resultados da Pesquisa. 


\subsection{Análise do Desempenho de Carteiras (Retorno das Ações) das empresas IPO}

Objetivando analisar a relação entre o gerenciamento de resultados contábeis e o retorno das ações das empresas IPO nos três anos posteriores ao lançamento das ações foi utilizada a classificação das empresas em tercis conforme o nível de accruals discricionários apurados com base no Modelo de Performance-Matching (2005) dado que este modelo apresentou melhores resultados em relação ao Modelo de Jones Modificado (1995). A classificação das empresas em tercis objetiva distinguir e sinalizar as empresas gerenciadoras (tercil 3) e as não gerenciadoras (tercil 1), conforme metodologia utilizada na presente pesquisa.

Em ambos os anos, as empresas do tercil 3, com maiores níveis de accruals discricionárias, obtiveram desempenho inferior no que tange retorno das ações se comparado ao desempenho das empresas IPO do tercil 1, com menores níveis de accruals discricionários. Este comportamento pode ser observado na Tabela 5.

Tabela 5. Comparações do retorno médio das ações das empresas IPO nos tercis 1 e 3

\begin{tabular}{c|c|c|c}
\hline Retorno das Ações & Ano +1 & Ano +2 & Ano +3 \\
\hline Tercil 1 & $14.44 \%$ & $56.86 \%$ & $68.99 \%$ \\
\hline Tercil 3 & $-1.06 \%$ & $-25.45 \%$ & $-9.89 \%$ \\
\hline Diferença & $15.50 \%$ & $82.31 \%$ & $78.88 \%$ \\
\hline Prob $(\boldsymbol{T}>\boldsymbol{t})$ & 0.1542 & $0.0009 *$ & $0.0011 *$ \\
\hline Estatística $\boldsymbol{t}$ & 1.0282 & 3.3049 & 3.2273 \\
\hline
\end{tabular}

$\left(^{*}\right)$ e (**) Denota significância estatística ao nível de 5\% e 10\%, respectivamente.

Fonte: Resultados da pesquisa.

\section{Considerações finais}

Observou-se, tanto com base no Modelo de Jones Modificado, quanto com base no Modelo de Performance-Matching, que os níveis de acumulações discricionárias nos períodos imediatamente ao redor do evento do IPO (anos $-1,0$ e +1$)$ são maiores do que os níveis apurados nos períodos posteriores ao evento $(\operatorname{anos}+2 \mathrm{e}+3)$ em que os incentivos para gerenciar resultados por parte dos administrados reduzem consideravelmente.

Este padrão foi confirmado pelo teste $t$ para a diferença de médias que apontou que os níveis médios de accruals discricionários são maiores e distintos estatisticamente para os anos $-1,0$ e +1 se comparados com os níveis médios apurados para os anos +2 e +3 . Entretanto, para a amostra, obtiveram-se resultados estatísticos para confirmar a hipótese, segundo a qual 
existem evidências de que as empresas brasileiras que realizaram IPO apresentaram maiores níveis de accruals discricionários nos anos que antecederam e marcaram o IPO.

Quanto à avaliação dos indicadores de desempenho econômico-financeiro, percebeu-se, depois de analisados todos os resultados relacionados às métricas de performance das empresas IPO, que existem evidências significativas para não rejeitar a hipótese $(\mathrm{H} 2)$ de que as companhias que realizaram IPO apresentaram melhor desempenho econômico-financeiro nos anos que precederam a oferta pública. Isso foi inferido a partir do teste $t$ para a diferença entre as médias antes e depois do IPO para os indicadores de ROA, Margem do EBITDA, LPA e P/L. Todos estes indicadores demonstraram maiores médias nos períodos que antecedem e marcam o IPO do que em períodos posteriores ao lançamento.

Quanto a análise da performance das empresas IPO entre o tercil 1 (empresas que não gerenciaram) e o tercil 3 (empresas que gerenciaram agressivamente seus resultados), percebese que também há distinção no comportamento das métricas de performance entre estas empresas, como aponta Teoh, Welch e Wong (1998).

Destarte, a partir dos resultados obtidos para todas as métricas de performance relacionadas, pode se inferir que os gestores podem estar gerenciando seus resultados no intuito de melhorar estes indicadores nos momentos que antecedem e marcam o lançamento das ações objetivando reação positiva do mercado, ou seja, ação oportunista para gerenciar resultados contábeis nos anos que antecederam e marcaram o IPO.

Cabe destacar ainda que a análise dos modelos de Jones Modificado e de PerformanceMatching também revelaram maiores indícios de gerenciamento nos momentos que antecedem e marcam o IPO. Em seguida foi analisado o retorno das ações das empresas IPO nos três anos posteriores ao lançamento das ações. Neste contexto, também foi analisada a relação entre o gerenciamento de resultados ou nível de discricionariedade, medido pelos accruals discricionários e o retorno das ações das empresas IPO. Foi utilizada a classificação das empresas em tercis que objetivou distinguir e sinalizar as empresas gerenciadoras (tercil 3) e não gerenciadoras (tercil 1).

Observou-se, de forma aparente, para todos os períodos analisados $(\operatorname{anos}+1,+2$ e +3$)$, que o retorno médio das ações das empresas IPO classificadas no tercil 1 (empresas com menores níveis de accruals discricionários - não gerenciadoras) foram maiores do que o retorno médio apresentado pelas empresas IPO classificadas no tercil 3 (empresas com maiores níveis de accruals discricionários - gerenciadoras). 
Enfim, é importante ressaltar que, análises relacionadas ao preço das ações dessas empresas objetivam elucidar o quão importante é, para os investidores no mercado de capitais, compreender o gerenciamento de resultados e as consequências de suas reversões. A partir da análise dos retornos das ações entre empresas que supostamente gerenciaram seus resultados e empresas que não gerenciaram seus resultados, poderá ser melhor elucidado como o gerenciamento de resultados pode interferir no desempenho das ações (comportamento do preço dessas ações ao longo do tempo).

\section{Referências}

Aharony, J. C.; Lin, C.; Loeb, M. Initial Public Offerings, accounting choices, and earnings management. Contemporary Accounting Research, n. 10, v. 1 (Fall), p. 61-81, 1993.

Aldrighi, D. M. et al. As ofertas públicas iniciais na Bovespa no período recente: características das empresas, estrutura de propriedade e de controle, e desempenho. In: XXXVIII Encontro Nacional de Economia - ANPEC - Associação Nacional dos Centros de Pós-Graduação em Economia, 2010, Salvador. ANPEC 38, 2010.

Alhadab, M.; Clacher, I.; Keasey, K. Real and Accrual Earnings Management and IPO Failure Risk. Fev., 2013. Disponível em: SSRN: http://ssrn.com/abstract=2225411.

Bispo, O. N. de A.; Gerenciamento de Resultados Contábeis e o Desempenho das Ofertas Públicas Subsequentes de Ações em Empresas Brasileiras. 2010.143 f. Dissertação (Mestrado Acadêmico) - Faculdade de Ciências Econômicas, Universidade Federal de Minas Gerais, Minas Gerais, 2010.

BM\&FBOVESPA, 2014. Ofertas Públicas de Distribuição de Ações. Disponível em: http://www.bmfbovespa.com.br/pt-br/mercados/acoes/ofertas-publicas/ofertaspublicas.aspx?idioma=pt-br Acesso em: 03.01.2014.

Costa Jr, N. C. A. da; Neves, M. B. E. das. Variáveis fundamentalistas e os retornos das ações. Revista Brasileira de Economia. v.54, n.1, Rio de Janeiro, 2000.

Dechow, P. M.; Sloan, R. G.; Sweeney, A. P. Detecting Earnings Management. The Accounting Review, Sarasota, v. 70, n. 2, p. 193-225, April, 1995.

Dechow, P. M.; Richardson, S. A.; Tuna, I. Why are earnings kinky? An examination of the earnings management explanation. Review of Accounting Studies, v. 8, n. 2-3, jun-sep., 2003.

Galdino, R. de L. Ofertas Públicas Iniciais "IPOs” na BM\&FBovespa: um enfoque geral e do ponto de vista do investidor individual. Monografia. Departamento de Ciências Econômicas. Universidade Federal de Santa Catarina. Florianópolis, 2010. 
Gioielli, S. P. O.; Carvalho, A. G. de; Sampaio, J. O. Capital de risco e gerenciamento de resultados em IPOs. v.10, n.4, p. 32- 68, Vitória-ES, Out/Dez. 2013.

Healy, P. M.; Wahlen, J. M. A review of the earnings management literature and its implications for standard setting. Accounting Horizons, v. 13, n. 4, p.365-383, 1999.

Hochberg, Y. V. Venture capital and corporate governance in the newly public firm. Review of Finance, v. 16, n. 2, p. 429-480, 2011.

Iudícibus, S. de; Lopes, A. B. Teoria avançada da contabilidade. São Paulo: Atlas, 2004.

Jones, J. Earnings Management During Import Relief Investigations. Journal of Accounting Research. Chigaco, v. 29, n. 2, p. 193-228, Autumn, 1991.

Kothari, S. P.; Leone, A. J.; Wasley, C. E. Performance matched discretionary accrual measures. Journal of Accounting and Economics, v. 39, p.163-197, 2005.

Martinez, A. L. "Gerenciamento" dos Resultados Contábeis: estudo empírico das companhias abertas brasileiras. 2001. 150 f. Tese (Doutorado) - Faculdade de Economia, Administração e Contabilidade da Universidade de São Paulo, São Paulo, 2001.

Paulo, E. Gerenciamento de resultados e a oferta pública de ações pelas companhias abertas brasileiras. In: ENCONTRO DA ASSOCIAÇÃO NACIONAL DE PÓS-GRADUAÇÃO E PESQUISA EM ADMINISTRAÇÃO, 30, 2006, Salvador. Anais. CD-ROM.FICA 2876.

Ronen, J.; Yaari, V.; Earnings Management: emerging insights in theory, practice, and research. Springer Series in accounting scholarship; SPRINGER; New York, 2008.

Teoh, S. H.; Welch, I.; Wong T. J. Earnings Management and the Long-Run Market Performance of Initial Public Offerings. The Journal of Finance, v. LIII, n. 6, December, 1998.

Teoh, S. H.; Wong, T. J.; Rao, G. R. Are accruals during Initial Public Offerings Opportunistic? Review of Accounting Studies, v. 3, p.175-208, 1998.

Zielinski, K. Long run stock performance of initial public offerings: an international insight. Trends of the World Economy - Key Problems of Selected Economies, Regions and Industries, $5^{\text {a }}$ Edition, 2013. 